\title{
Performance Evaluation of Electronically Tunable Filter Using CCCII in 45nm CMOS Technology for Wi-Fi Applications
}

\author{
Jyoti Sharma ${ }^{1}$, Kshitij Sharma ${ }^{2}$ \\ ${ }^{1}$ Assistant Professor, Birla Institute of Technology, Mesra-Ranchi, Jaipur Campus, Malviya Nagar, 302017, Rajasthan, India \\ ${ }^{2}$ B.E. student, ECE department, Birla Institute of Technology, Mesra- Ranchi, Jaipur campus, Malviya Nagar, 302017, Rajasthan, India
}

\begin{abstract}
Second generation Current Controlled Current conveyors are getting compelling recognition due to their AC performances with better linearity, high sensitivity, wider and nearly constant bandwidth, high slew rate, reduced supply voltage (nearly $0.5 \mathrm{~V})$, less chip area and larger dynamic range. CCCIIs are electronically tunable i.e. its parasitic resistance at current input port can be adjusted by an input bias current making it useful for wide range of applications. This paper presents an approach of designing a universal filter using CCCII as its active building block. Filter has been tuned for Wi-Fi applications and realised in 45nm CMOS technology while performances were examined through HSPICE simulations.
\end{abstract}

Keywords: CCCII+, CCCII-, CCCII \pm , Electronic tunability, Universal filter

\section{Introduction}

A versatile current mode circuit, commonly known as Current Conveyor gains acceptance as theoretical as well as practical building block. Current Conveyor consists of one high and one low impedance input and one high impedance output ; hence, acts as an apt element for both voltage mode and current mode circuits. The classical op-amps suffer from confined gain- bandwidth product and low slew rate. Therefore, they remain undesirably at higher frequencies.

Nowadays supply voltage has become a severe concern in electronic circuit design scenario specifically for portable and battery efficient equipment and the breakdown voltage of short channel MOS transistors. Because of the increasing importance of low voltage operating circuit, current mode techniques are more convenient for such purposes as compared to voltage mode circuits. As a result of it, current mode circuits are becoming more popular and vital due to their huge dynamic range, higher bandwidth, greater linearity, simple circuitry, less power consumption and reduced chip area in comparison with their voltage mode counterparts such as Operational Amplifiers. Of late years, with advent of CMOS technology, current mode devices are gaining considerable significance in circuit designs.

\section{Description of Current Controlled Current Conveyor}

Fig 1. depict the symbol of the second generation CCCII. A CCCII based circuit, no matter whether positive, negative or dual output, gives electronic tunability and wide adjustable range of its parasitic resistance at X-terminal. Since CCCII doesn't require external resistors, therefore, it is very appropriate in the designing of integrated filters and oscillators. Moreover, as the CCCII is current controlled source, the CCCII based circuit is acceptable for high frequency operation.

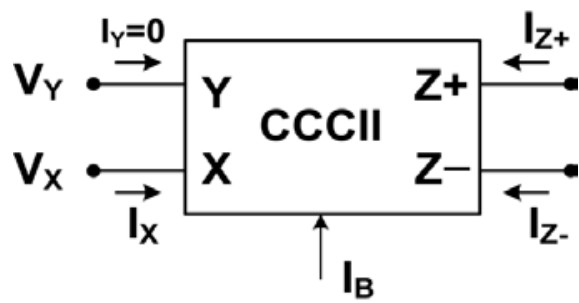

Figure 1: Symbol of CCCII

Circuit designers are lured by these interesting characteristics of CCCII. The following matrix depicts the relationship between the voltage and current variables at input and output ports $\mathrm{X}, \mathrm{Y}$ and $\mathrm{Z}$ of the CCCII,

$$
\left[\begin{array}{c}
V_{X} \\
I_{Y} \\
I_{Z} \pm
\end{array}\right\rfloor=\left[\begin{array}{ccc}
R_{X} & 1 & 0 \\
0 & 0 & 0 \\
\pm 1 & 0 & 0
\end{array}\right]\left\lfloor\begin{array}{c}
I_{X} \\
V_{Y} \\
V_{Z}
\end{array}\right\rfloor
$$

where the sign \pm refers to plus type and minus type CCCII respectively and $\mathrm{Rx}$ stands for intrinsic resistance at $\mathrm{X}$ terminal. $\mathrm{Rx}$ is tunable by a supplied bias current $\mathrm{Ib}$ which can be expressed through a class $A B$ translinear loop commonly used as input section, where

$$
\mathrm{R}_{\mathrm{X}}=\frac{1}{2 g_{m}}=\frac{1}{\sqrt{8 \beta_{n} I_{b}}}
$$

where, $\quad \beta_{n}=\mu_{n} C_{o x} \frac{W}{L}$ is the physical parameter of the MOS transistor.

\section{CMOS implementation of CCCII}

The schematics of standard CMOS implementation of positive, negative and dual output CCCII are given by Fig 2, 3 and 4 respectively. Since both in common source and 


\section{International Journal of Science and Research (IJSR) \\ ISSN (Online): 2319-7064}

Index Copernicus Value (2013): 6.14 | Impact Factor (2014): 5.611

common gate amplifier configurations, the output signal is a current, hence MOS transistors are more suitable particularly for processing current rather than voltages. On the contrary, common drain amplifier configurations are almost useless at low supply voltages because of the bulk effect embedded in typical CMOS processes. Additionally, MOS current mirrors are more accurate and less sensitive to process variation rather than bipolar current mirrors because with the latter, the base currents reduce the accuracy.

Thus, MOS transistor circuits should be simplified by using current signals as compared to voltage signals. In case when the signal is conveyed as a current, the voltages in MOS transistor circuits are proportional to the square root of the signal provided saturation region operation is assumed for the devices. Consequently, a compression of voltage signal swing and a reduction of supply voltage is possible. Moreover, maximum usable frequency of MOS will be achieved sooner with very high values for its drain currents.

Fig 2 shows the circuit which comprises of one mixed translinear loop(transistors M1 to M4) as input cell. Two current mirrors(transistors M5, M6 and M8, M9) allow the mixed loop to be dc biased by the current Ib. The input cell present a high level impedance input port $\mathrm{Y}$ and a low impedance input port $\mathrm{X}$ which acts as a voltage follower. The output $\mathrm{Z}$ that copies the current flowing through port $\mathrm{X}$ is achieved in the traditional manner using two complementary current mirrors.

As shown in Fig 3, current mirrors are build up of M11, M12 and M15, M17 and M14, M16 and M10, M13 are cross coupled to generate negative current at $\mathrm{Z}$. On the other hand, current mirrors in Fig 4 generate both types of output.

For implementation of the filter, the class AB type CCCII \pm circuit adopted is shown in Figure 4, and is readily available in literature. It's bipolar version containing both positive as well as negative output terminal has been studied by many authors, $[12,13]$. It's CMOS version can be found in the references $[5,10]$. In the present work, this circuit is redesigned in $45 \mathrm{~nm}$ CMOS technology and is simulated and verified using HSPICE [14].

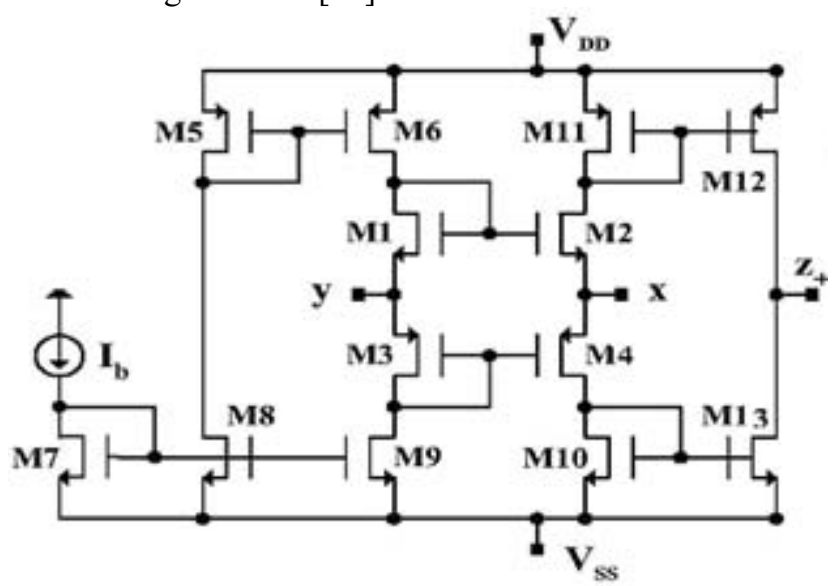

Figure 2: CMOS based circuit of CCCII+

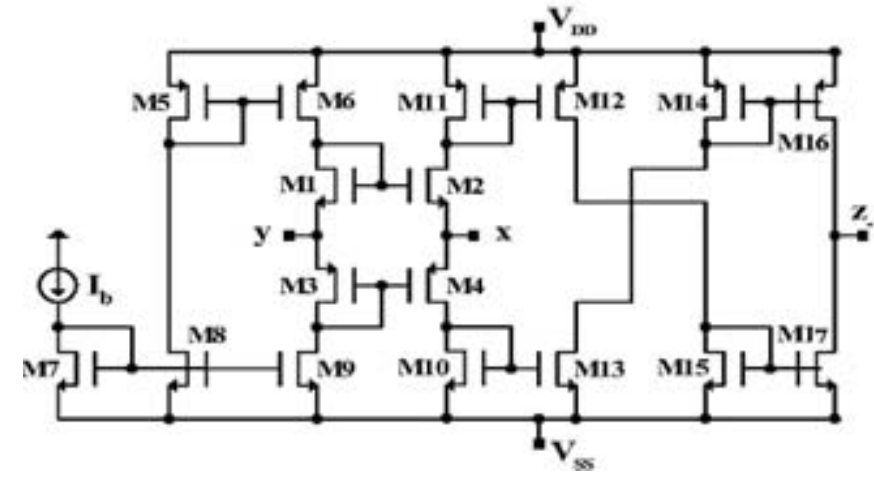

Figure 3: CMOS based circuit of CCCII-

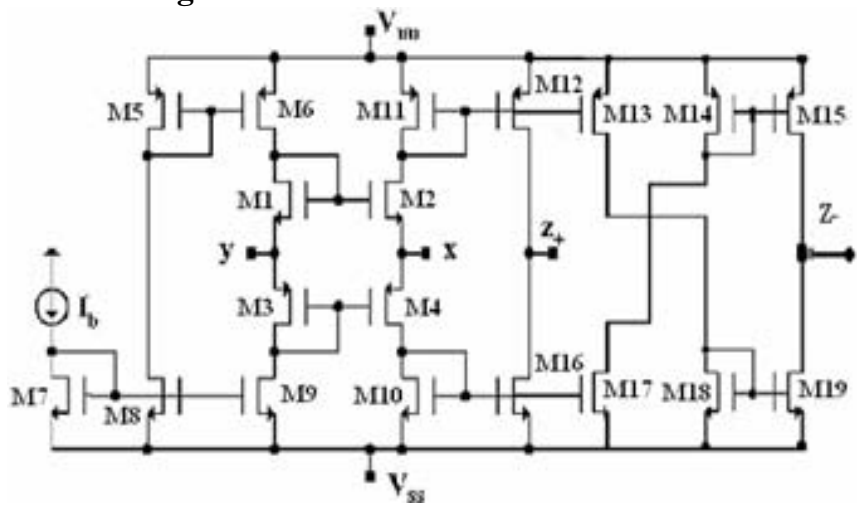

Figure 4: CMOS based circuit of CCCII \pm

\section{Analysis of CCCII}

Fig. 5, 6, and 7 show the transient, AC and DC analysis of $\mathrm{CCCII} \pm$ respectively. $\mathrm{Vdd} / \mathrm{Vss}$ is set to $0.54 \mathrm{~V}$ and biasing current is $10 \mu \mathrm{A}$.Transient analysis has been carried out with $100 \mathrm{MHz}$ sinusoidal input, for which the current relationship equation i.e., $\mathrm{Iz}=+\mathrm{Ix}, \mathrm{Iz}=-\mathrm{Ix}$ and $\mathrm{Iz}= \pm \mathrm{Ix}$ is successfully verified.

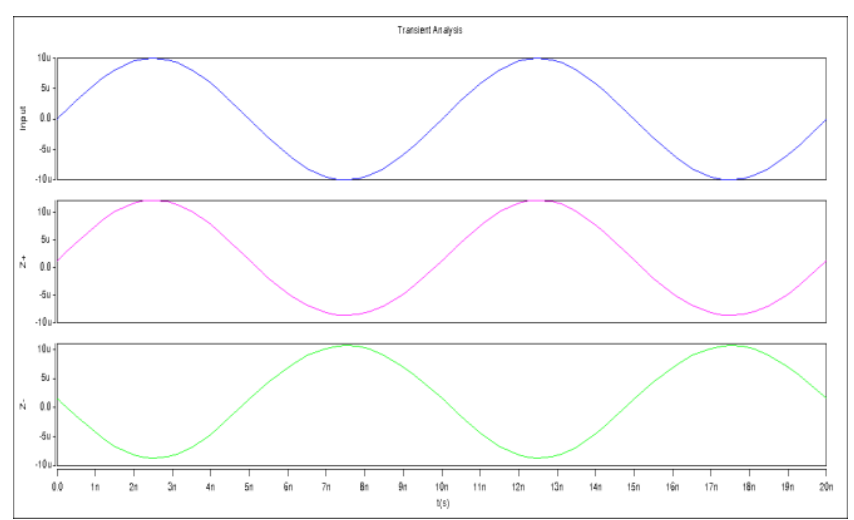

Figure 5: Transient analysis of DOCCCII

$\mathrm{AC}$ analysis for the CMOS-based $\mathrm{CCCII} \pm$ reveals excellent conformity between the input current (Ix) and the output current (Iz) and the bandwidth came out to be $28.9 \mathrm{Ghz}$. DC analysis has also been done to find the linearity between input and output ports. So in this way CCCII \pm verified the current relationship equation i.e. $\mathrm{Iz}=+\mathrm{Ix}, \mathrm{Iz}=-\mathrm{Ix}$ and $\mathrm{Iz}= \pm \mathrm{Ix}$ respectively. 


\section{International Journal of Science and Research (IJSR) \\ ISSN (Online): 2319-7064}

Index Copernicus Value (2013): 6.14 $\mid$ Impact Factor (2014): 5.611

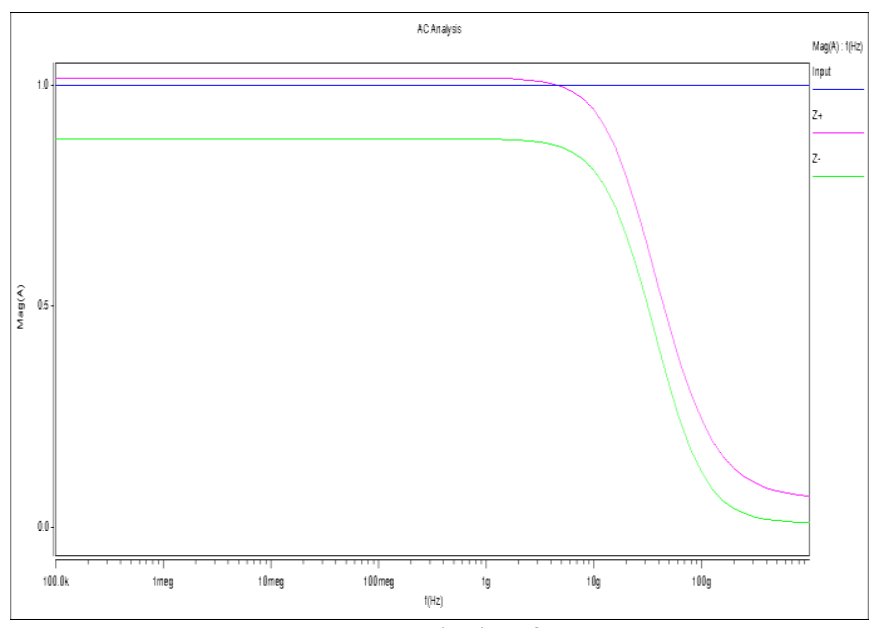

Figure 6: $\mathrm{AC}$ analysis of DOCCCII

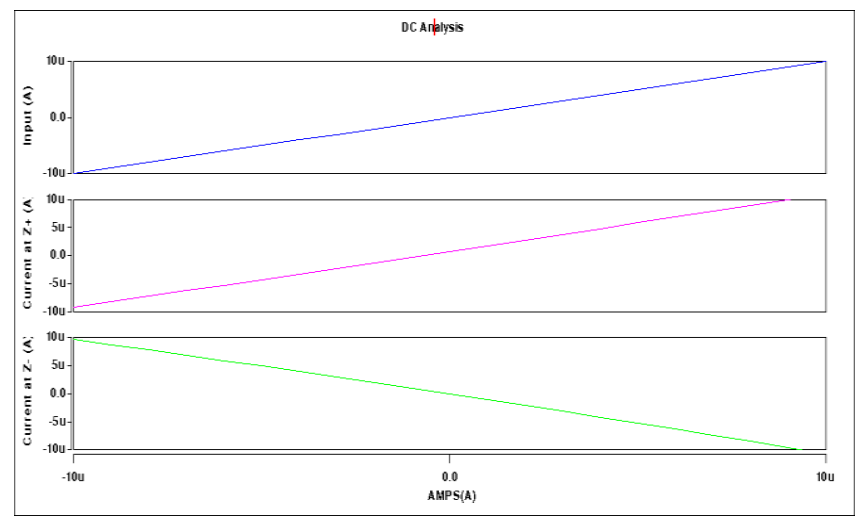

Figure 7: DC analysis of DOCCCII

\subsection{Performance Comparison at different Technologies}

Performance analysis of CCCII \pm has been done at $180 \mathrm{~nm}$, $90 \mathrm{~nm}$ and $45 \mathrm{~nm}$ CMOS technology. Power supplies, bias currents and the obtained $3-\mathrm{dB}$ bandwidth are compared in Table 1.

It is observed that as there is improvement in technology from $180 \mathrm{~nm}$ to $45 \mathrm{~nm}$, biasing current decreases from $30 \mathrm{u}$ to $10 \mathrm{u}$. Supply voltage is also reduced to $0.45 \mathrm{~V}$ which shows that $\mathrm{CCCII} \pm$ at $45 \mathrm{~nm}$ is power efficient as well. $3-\mathrm{db}$ bandwidth increases from $5.4 \mathrm{Ghz}$ to $29.8 \mathrm{Ghz}$ which shows that it is very suitable for high frequency applications and due to its excellent electronic tunability property ( shown in fig. 8) its frequency can be set to a specific application based frequency (for eg. $2.4 \mathrm{Ghz}$ in case of $\mathrm{Wi}-\mathrm{Fi}$ ).

Table 1: Performance Comparison at different technologies

\begin{tabular}{|c|c|c|c|}
\hline & $\mathbf{1 8 0 n m}$ & $\mathbf{9 0 n m}$ & $\mathbf{4 5 n m}$ \\
\hline $\mathbf{I}_{\mathbf{b}}$ & $30 \mu$ & $18 \mu$ & $10 \mu$ \\
\hline Vdd/Vss & $\pm 0.72 \mathrm{~V}$ & $\pm 0.54 \mathrm{~V}$ & $\pm 0.45 \mathrm{~V}$ \\
\hline Bandwidth & $5.4 \mathrm{Ghz}$ & $12.8 \mathrm{Ghz}$ & $29.8 \mathrm{Ghz}$ \\
\hline
\end{tabular}

\section{Application as a Universal filter}

CCCIIs are broadly used as fundamental active building blocks to realize various current-mode active filters. The universal filter is one of the most popular analog filters as it can provide various standard functions like low pass, high pass, band pass, band reject and all pass.
In this section, a current mode universal filter has been implemented with single input and three different outputs for low, high and band pass filters. Implementation of Universal filter is depicted in Fig.8 using only two CCCII \pm and two capacitors as the dual-output current conveyors are useful in the derivation of current-mode single input and three output filters using a decreased number of active components $[8,9$, $10]$.

The analysis i.e. transfer function of the Universal filter can be summarized as follows:

$$
\begin{aligned}
& \frac{I_{H P}}{I_{\text {in }}}=\frac{\left(-s^{2}\right)}{\left(s^{2}+{ }^{S} / R_{X 1} C_{1}+1 / R_{x 1} R_{X 2} C_{1} C_{2}\right)} \\
& \frac{I_{L P}}{I_{\text {in }}}=\frac{\left(-1 / R_{x 1} R_{X 2} C_{1} C_{2}\right)}{\left(s^{2}+{ }^{s} / R_{x 1} C_{1}+1 / R_{x 1} R_{x 2} C_{1} C_{2}\right)} \\
& \frac{I_{B P}}{I_{\text {in }}}=\frac{\left(s / R_{x 1} c_{1}\right)}{\left(s^{2}+s^{s} / R_{x 1} c_{1}+1 / R_{x 1} R_{x 2} C_{1} c_{2}\right)}
\end{aligned}
$$

In addition to this, the response of band-pass i.e. notch filter can be obtained by connecting $\mathrm{I}_{\mathrm{HP}}$ \& $\mathrm{I}_{\mathrm{LP}}$ together as follows:

$$
\frac{I_{B R}}{I_{\text {in }}}=\frac{-\left(s^{2}+1 / R_{X 1} R_{X 2} c_{1} c_{2}\right)}{\left(s^{2}+s^{s} / R_{x 1} c_{1}+1 / R_{x 1} R_{x 2} C_{1} c_{2}\right)}
$$

In the same way, all pass filter transfer functions can be implemented by connecting $\mathrm{I}_{\mathrm{HP}}, \mathrm{I}_{\mathrm{LP}}, \mathrm{I}_{\mathrm{BP}}$ together or $\mathrm{I}_{\mathrm{BR}}$ and $\mathrm{I}_{\mathrm{BP}}$ together as follows:

$$
\frac{I_{A P}}{I_{\text {in }}}=\frac{-\left(s^{2}-s / R_{x 1} c_{1}+1 / R_{x 1} R_{x 2} c_{1} c_{2}\right)}{\left(s^{2}+s^{s} / R_{x 1} c_{1}+1 / R_{x 1} R_{x 2} c_{1} c_{2}\right)}
$$

Table 2: Comparison between different filters

\begin{tabular}{|c|c|c|c|}
\hline & High pass & Low pass & Band pass \\
\hline Peak frequency & $10.2 \mathrm{Ghz}$ & $850 \mathrm{Mhz}$ & $3.16 \mathrm{Ghz}$ \\
\hline Bandwidth & $8.6 \mathrm{Ghz}$ & $4.8 \mathrm{Ghz}$ & $2.82 \mathrm{Ghz}$ \\
\hline
\end{tabular}

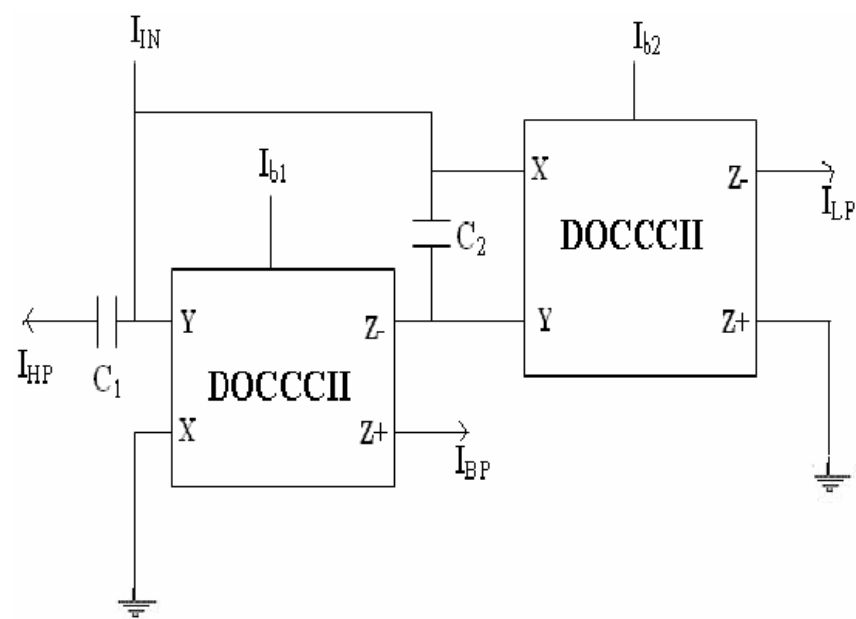

Figure 8: Universal filter using DOCCCII

The natural frequency $\omega_{0}$, the bandwidth $\frac{\omega_{0}}{Q}$ and the quality factors are given as below: 


\section{International Journal of Science and Research (IJSR) \\ ISSN (Online): 2319-7064}

Index Copernicus Value (2013): 6.14 | Impact Factor (2014): 5.611

$$
\begin{gathered}
\omega_{0}=\left(1 / R_{x 1} R_{x 2} C_{1} C_{2}\right)^{1 / 2} \\
\omega_{0} / Q=1 / R_{x 1} C_{1} \\
Q=\left(R_{x 1} C_{1} / R_{X 2} C_{2}\right)^{1 / 2}
\end{gathered}
$$

The above mentioned equations clearly indicate that $\frac{\omega_{0}}{Q} \& \omega_{0}$ can be adjusted by the bias currents of $\mathrm{I}_{\mathrm{b} 1}$ and $\mathrm{I}_{\mathrm{b} 2}$ of the respective \pm CCCII. Transmission of universal filter is given by -

$$
T(s)=\frac{\left(a_{2} s^{2}+a_{1} s+a_{0}\right)}{s^{2}+\frac{\omega_{0}}{Q} s+\omega_{0}^{2}}
$$

In this implementation, $\mathrm{a}_{2} \mathrm{a}_{1 \&} \mathrm{a}_{0}$ are $1,1 / R_{x 1} C_{1}$ and $\omega_{0}{ }^{2}$ respectively.

For the successful implementation of universal filter, the following values of capacitors \& bias currents have been used.

$$
\begin{aligned}
& \mathrm{C}_{1}=\mathrm{C}_{2}=5 \mathrm{fF} \\
& \mathrm{I}_{\mathrm{b} 1}=\mathrm{I}_{\mathrm{b} 2}=1 \mathrm{u}
\end{aligned}
$$

Fig. 9 shows the adjustability in low pass filter as its response in changing with the variation in bias currents. This also shows how good CCCII acts as an electronically tunable active building block. Fig 10, 11 and 12 depict frequency responses for low and high, notch filter and band pass filter respectively. After simulation with HSPICE using $45 \mathrm{~nm}$ CMOS parameters, we get the following conclusions.

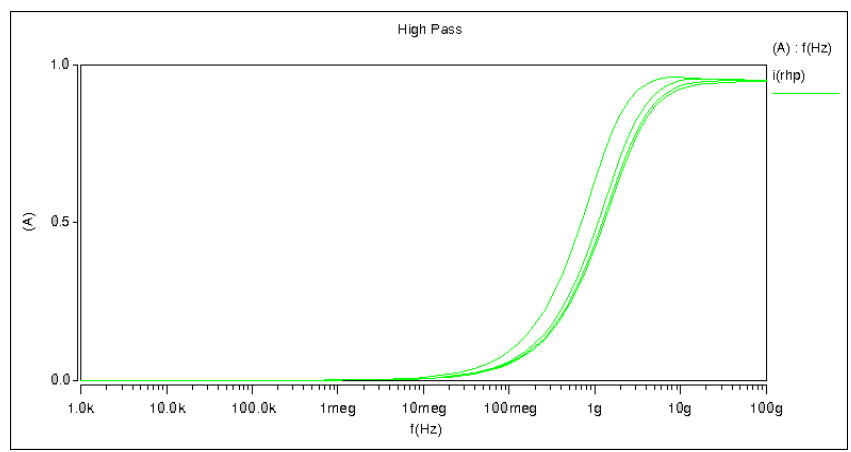

Figure 9: High pass filter response with variation in bias current

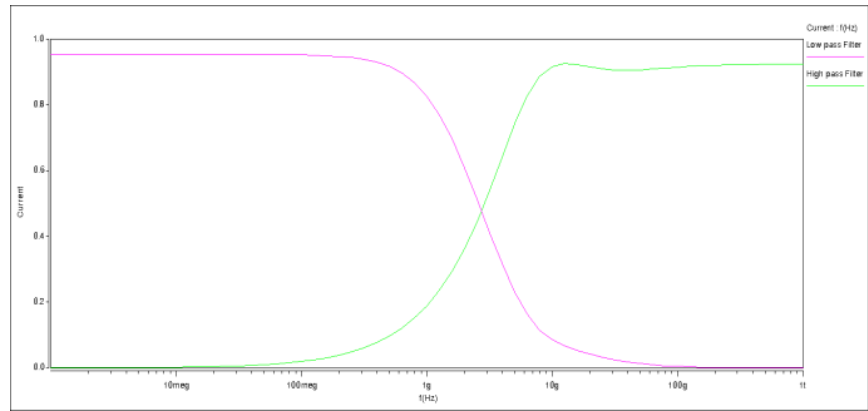

Figure 10: Frequency response of high pass and low pass filter

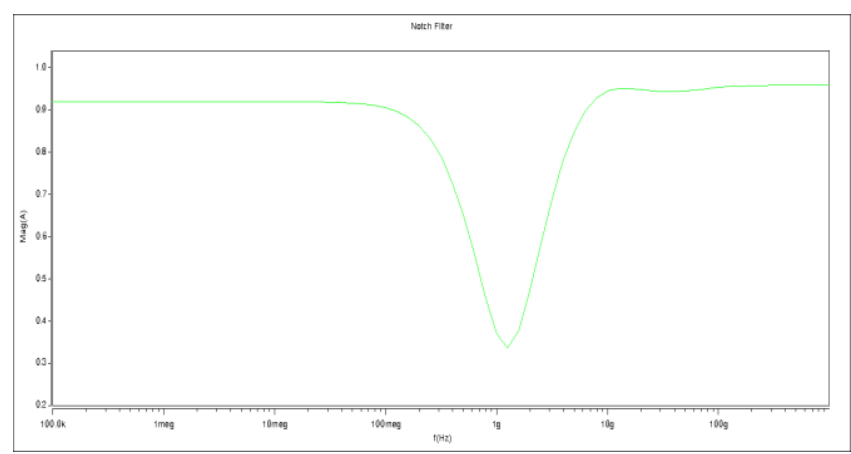

Figure 11: Frequency response of notch filter

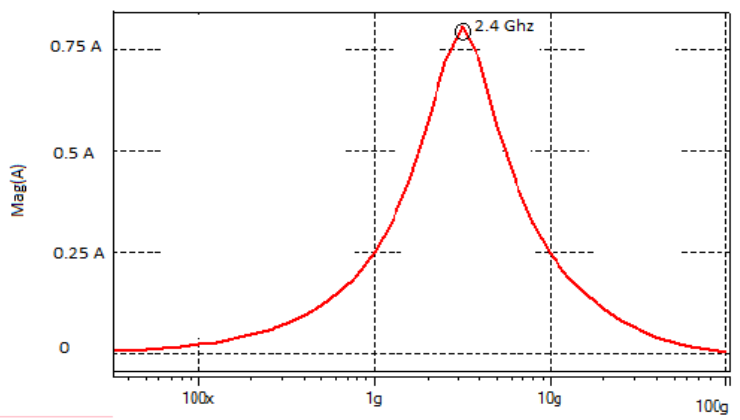

Figure 12: Frequency response of band pass filter

Results are showing good response and resemblance with the expected values. Now band pass filter has been tuned at 2.4 Ghz frequency so that it can be used for Wi-Fi applications.(Fig. 12). The values of capacitors are varied in accordance to the desired frequency.

\section{Conclusions}

In this paper, Second generation Current Controlled Current conveyor is implemented using the $45 \mathrm{~nm}$ CMOS technology. The circuit uses $\pm 0.45 \mathrm{~V}$ DC supply and $10 \mathrm{uA}$ of biasing current. Transient, AC and DC analysis are carried out using HSPICE tool. The simulation results indicate the correct operation of the CCCII \pm circuit up to $38 \mathrm{GHz}$. A current mode universal filter is then implemented that employs CMOS-based CCCII \pm and capacitors. The filter can be configured to obtain three different outputs- low-pass, highpass and band-pass and by further updates band reject and all pass filter can also be made. The HSPICE simulation results confirmed the suitability of the current-mode universal filter for operation in the $2.4 \mathrm{GHz}$ band used by Wi-Fi standard. Thus the filter is suitable for the $\mathrm{Wi}-\mathrm{Fi}$ applications. The $\mathrm{CCCII} \pm$ can be used as an active building block in the designing of various analog circuits such as oscillators, rectifiers, instrumentation amplifiers etc.

\section{References}

[1] ABBAS, Z., G. SCOTTI, y M. OLIVIERI, . "Current controlled current conveyor (CCCII) and application using 65nm CMOS technology". World Academy of Science, Engineering and Technology. 2011, vol Vol. 55 ,

[2] ALlen, P.E. y D.R. HOLBERG, . CMOS Analog Circuit Design. New York: Oxford University Press, 2002. 


\section{International Journal of Science and Research (IJSR) \\ ISSN (Online): 2319-7064}

Index Copernicus Value (2013): 6.14 | Impact Factor (2014): 5.611

[3] BHATT, A.. "Design and analysis of CMOS current conveyor". Journal of Information, Knowledge and Research in ECE. Oct. 2013, vol Vol. 2, Issue 2,

[4] BR, STETTER, Pavel y LUKAS KLEIN, "Applications of non-inverting positive second generation current conveyor as a commercially available versatile active element". In Signals and Electronic Systems (ICSES), 2010 International Conference. 2010, p. 157-160.

[5] BULT, K.. "Analog design in deep sub-micron CMOS". Proc. European Solid-State Conf. 2001, p. pp. 126-132.

[6] K C, Smith y SEDRA A, . "The current conveyor - new building block". IEEE Proceedings. 1968, vol 56, p. 1368-1369.

[7] M. CHANG, C., H. HUANG, T., H. TU, S., L. HOU, C. y W. HORNG, J.. "Universal Active Current Filter using Single Second-Generation Current Controlled Conveyor". International Journal of Circuits, Systems and Signal Processing. 2007, vol Vol. 1, Issue 2, p. p.p. 194-198.

[8] EL-ADAWY, Ahmed A. y O. ELWAN, Hassan. "A novel fully differential current conveyor and applications for analog VLSI". Circuits and Systems II: Analog and Digital Signal Processing, IEEE Transactions. 2000, vol 4, p. 306-313.

[9] FABRE, A.. "Third- generation current conveyor: a new helpful active element". IEEE letters. 1995, p. 338-339.

[10] GRIGORESCU, L.. "Amplifiers built with current conveyors". Romania Journal of Physics. 2008, vol Vol. 53, No. 1-2, p. pp.109-113.

[11] A. JOHNS, David y KEN MARTIN, . Analog Integrated Circuit Design. Wiley India Pvt. Ltd., 1997.

[12] KUMAR, P., K. PAL, y K. GUPTA, G.. "High input impedence all-pass and notch filter configuration". Indian Journal of Pure \&amp; Applied Physics. May 2006, vol Vol. 44, p. pp. 398-401.

[13]H. KUNTMAN, H. y A. UYGUR, . "New possibilities and trends in circuit design for analog signal processing". International Conference on Applied Electronics. Sept. 2012, vol Vol. 1, No. 9, p. pp. 5-7.

[14]LATTENBERG y VRBA, . "Filters with current amplifiers for high-speed communication". International Conference on Systems and Mobile Communications and Learning Technologies. Apr. 2006, vol Vol. 150, No. 150 , p. pp. 23-29.

[15]H. MADIAN, A., A. MAHMOUD, S. y M. SOLIMAN, A.. "New 1.5-V CMOS second generation current conveyor based on wide range transconductor". Analog Integrated Circuit Signal Processing, Springer Science. Sep. 2006, vol Vol. 49, p. pp. 267-279.

[16] SEDRA, A y C SMITH, K. "A second generation current conveyor and its applications". IEEE trans. 1970, vol CT-17, p. 132-134.

[17]C. SMITH, K. y S. SEDRA, A.. "The Current Conveyor- A New Building Block". Proc. of the IEEE. Aug. 1968, vol Vol. 56, No. 8, p. pp. 1368-1369.

[18] J. SHARMA, M. S. ANSARI, AND J. B. SHARMA. "Electronically tunable resistor-less universal filter in $0.5 \mathrm{v} 32 \mathrm{~nm}$ CNFET". Fifth International Symposium on Electronic System Design (ISED), page 206207, Dec. 2014.
[19]J. SHARMA, M. S. ANSARI, AND J. B. SHARMA. "Current-mode electronically tunable resistor-less universal filter in $0.5 \mathrm{v} 32 \mathrm{~nm}$ CNFET". International Conference on Devices, Circuits and Communications (ICDCCom), page 16, Sept. 2014.

[20]J. SHARMA AND A. SHARMA. "Universal Filter Design using $45 \mathrm{~nm}$ CMOS-based DDCC for Bluetooth/Zigbee Applications". International Journal of Computer Applications(IJCA), Vol. 134, No. 13, January 2016. 